\title{
PAISAGISMO EM PERNAMBUCO INTRODUZINDO UM ROTEIRO PARA REFLEXÃO...
}

LUIS GOES VIEIRA FILHO

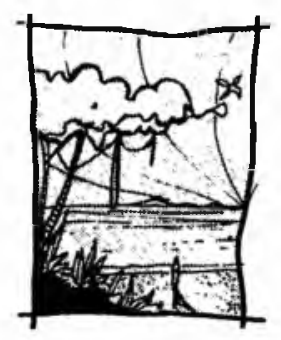

O paisagismo em Pernambuco não teve uma continuidade através de sua história como teve a arquitetura, com seus vários estilos e movimentos, resultando num legado paisagístico fragmentado, pouco pesquisado e com pouca ou nenhuma conservação. $O$ referencial histórico existe ainda que específico de certas épocas, tendo um breve apogeu na primeira metade do séc. XVII com os holandeses, outra ênfase na segunda metade do séc. XIX com os franceses e um clímax na primeira metade do séc. XX com os parques urbanos e a atuação do paisagista Roberto Burle Marx.

No início da colonização de Pernambuco foi criado por Duarte Coelho, o Horto de Olinda denominado Jardim da Aclimação, onde foram feitas várias pesquisas com plantas exóticas, principalmente frutíferas, as quais foram introduzidas gradativamente na região. No entanto, o acontecimento paisagístico mais importante da época colonial, mas durante o domínio holandês, se deu em Recife com a implantação do primeiro jardim projetado do continente americano: 0 do Palácio do Príncipe Maurício de Nassau. Esse jardim, segundo pesquisa feita por Liana Mesquita ${ }^{1}$ tinha estilo formal renascentista e usava árvores e palmeiras nativas ou adaptadas aos trópicos. O jardim do Palácio de Nova Friburgo foi uma obra extraordinária que inseriu o Recife colonial no contexto paisagístico das nações dominantes européias. Infelizmente, o jardim foi abandonado após a expulsão dos holandeses e o Palácio totalmente destruído em 1770 , e com o mesmo, o testemunho da mais importante intervenção paisagística do Novo Mundo, na época.

Sobre este tipo de jardim, Mc Harg afirma que: "Nos jardins renascentistas a autoridade do homem era visível pela imposição de uma simples geometria euclidiana sobre a paisagem (...). O homem impõe sua simples e envolvente ilusão de ordem, alcançada com grande arte, sobre uma desconhecida e desprezada natureza. $O$ jardim é oferecido como prova de superioridade do homem"2 


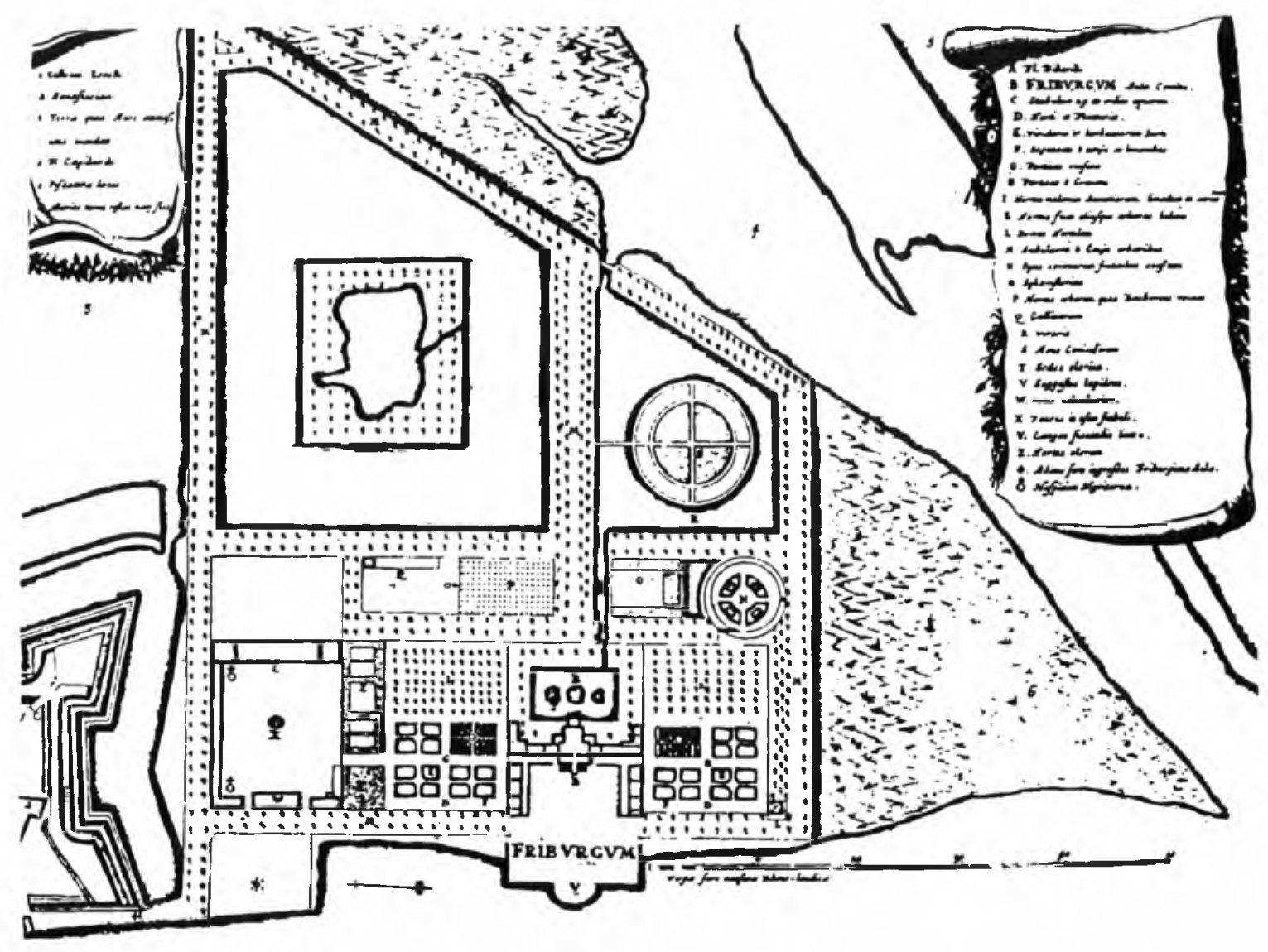

Desenho 1 Planta do Palácio Friburgo e suas dependências, horto e parque zoológico, atribuída a George Marcgraf, entre 1637-44, gravura em cobre, palácio e jardins de Nassau, projeto atribuído a Pieter Post, in: Baerle, Gaspar Van, Rerum per Octennium... Amsterdam, 1647

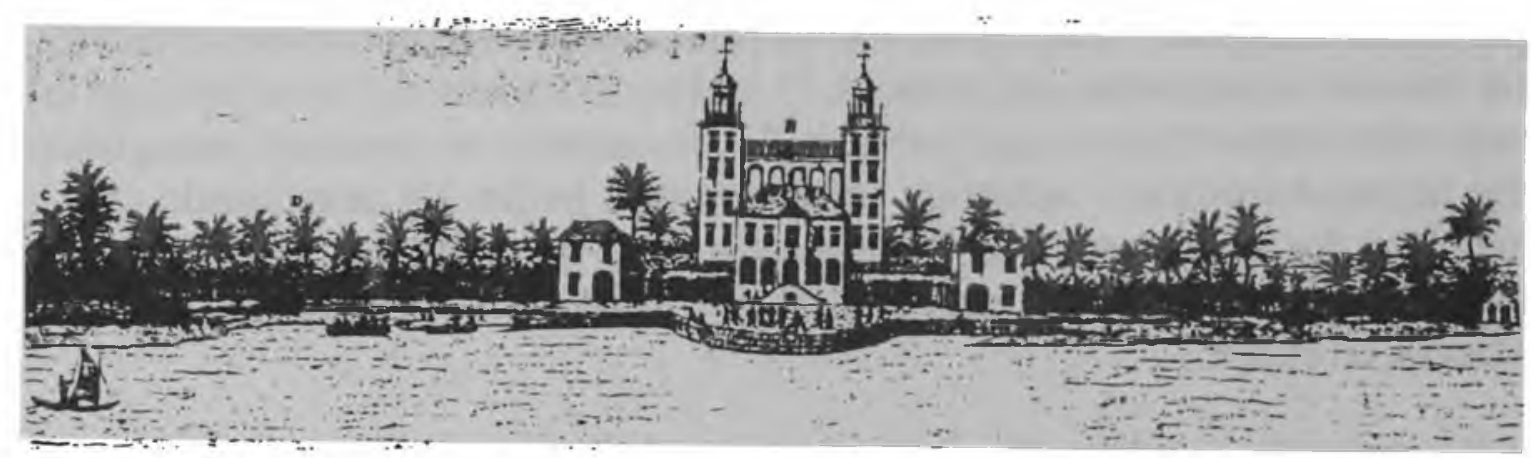

Desenho 2 - Frans Post - Vista do palácio Friburgo, entre 1637-44, gravura em cobre 330 x 510 mm, in: Baerle, Gaspar Van, Rerum per Octennium ... Amsterdam, 1647

Pernambuco volta a ser colônia de Portugal resultando um grande vazio no que concerne ao paisagismo, e na arquitetura como elemento formal relevante. Esse período é caracterizado pelos quintais arborizados com árvores frutíferas e pelos 
sítios nas áreas rurais, assim como pelo uso da vegetação com flores nos engenhos. A Igreja se destacou pelo tratamento dos claustros, pelo uso da vegetação na terra e em vasos. Esse período inerte, segundo o professor José Luiz da Mota Meneses $^{3}$ dura até a segunda metade do séc. XIX com o advento dos artistas franceses, contemporâneos de Vauthier ${ }^{4}$ tendo por resultado a criação de espaços urbanos como a praça XVII. Destaca-se nesse período o francês Beringer por projetar o jardim do Palácio do Campo das Princesas e da praça da República em 1875 (os quais foram reformados por Burle Marx na década de 30).

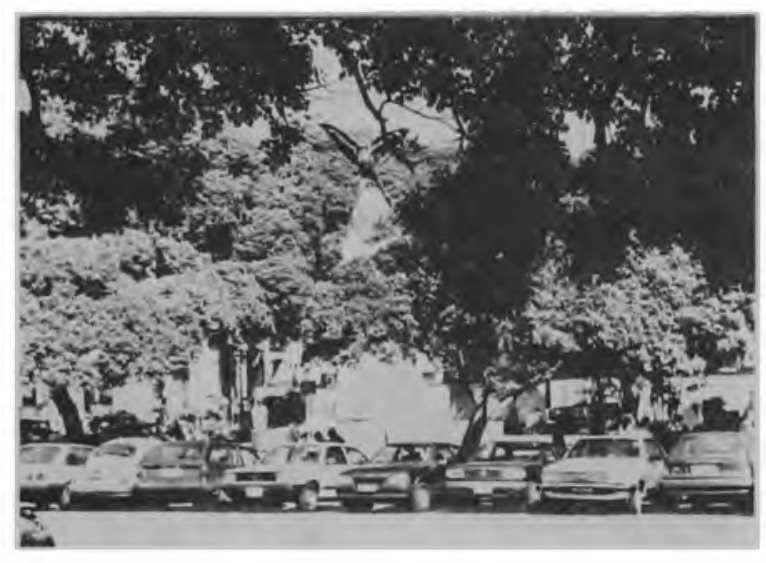

FOTO 1 Vista Geral Praça XVII de traçado clássico e bordejada por uma aléia de árvores exuberantes

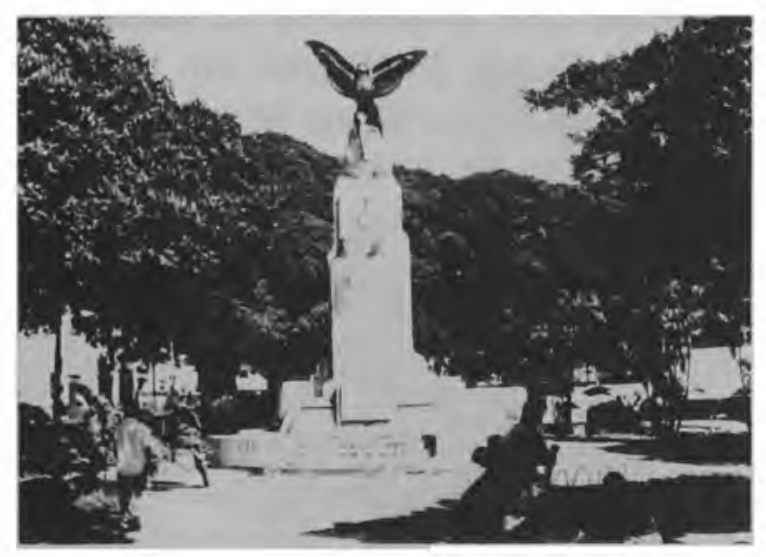

FOTO 2 - Praça XVII vista interna

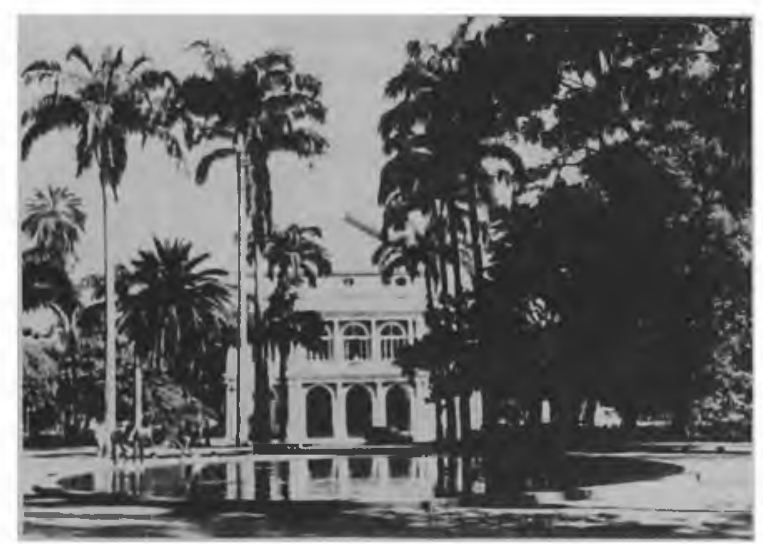

FOTO 3 - Praça da República Projeto do francês Beringer, foi construída na segunda metade do séc. XIX. dentro dos canônes das praças públicas da época 


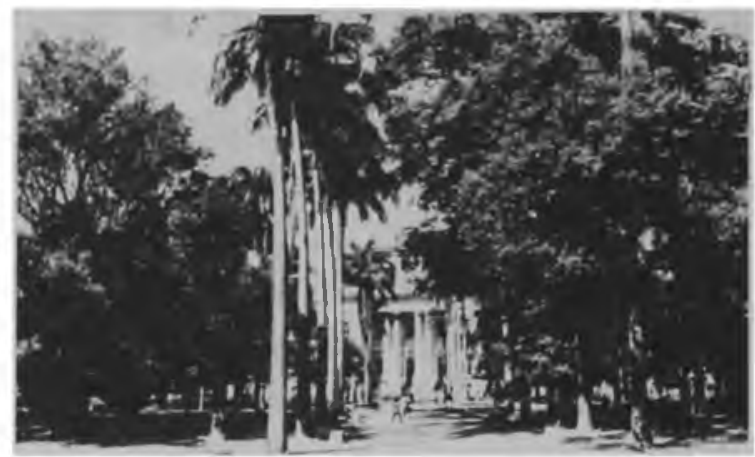

Foto 4 - Praça da República -

cortada por eixos definidos e uma

colunata de palmeiras imperiais que

unem visualmente os prédios

públicos circunvizinhos

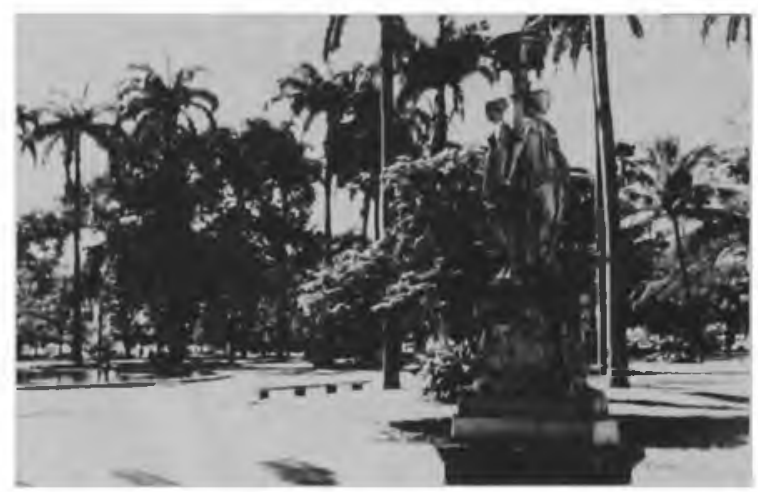

Foto 5 - Praça da República -

esculturas e lago central de forma circular sāo elementos típicos do Paisagismo "pitoresco" do séc. XIX, preservados durante a reforma empreendida por Burle Marx

No início do séc. XX, dois parques contribuíram com a melhoria da paisagem do Recife: o primeiro foi o Parque do Derby na década de 30 com um traçado sinuoso e bela arborização sendo parte dele reformado por Burle Marx (1934 a 1937): o segundo foi o Parque 13 de Maio concluído em 1939 com um traçado formal e uso de ficus e palmeiras imperiais. Nesse período o paisagismo residencial se dava ora imitando o estilo formal francês ora o orgânico inglês.

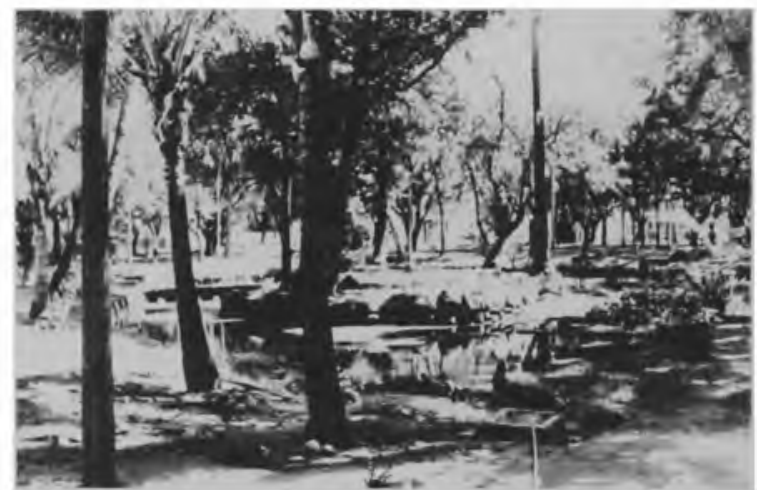

Foto 6 - Parque do Derby vista da Ilha dos Amores incorporando em seu traçado a estrulura formal do parque romântico e pitoresco do séc. XIX. ainda em voga em todas as cidades brasileiras nesta primeira metade de séc. XX 


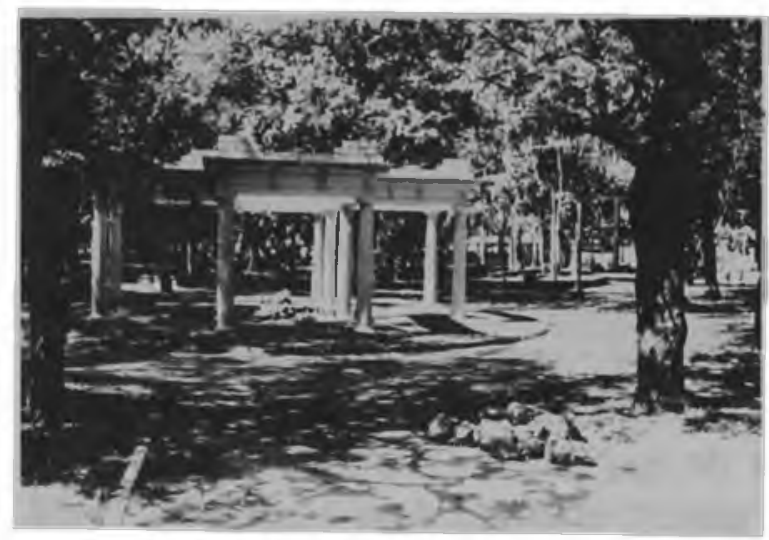

Foto 7 - Parque do Derby vista intema

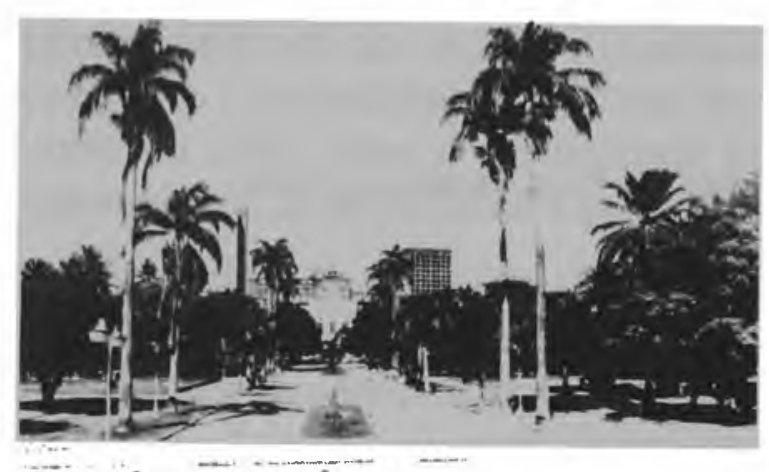

Foto 8 - Parque 13 de Maio - outro bom exemplo do tardio traçado clássico de parques no Brasil, cortado por un grande eixo

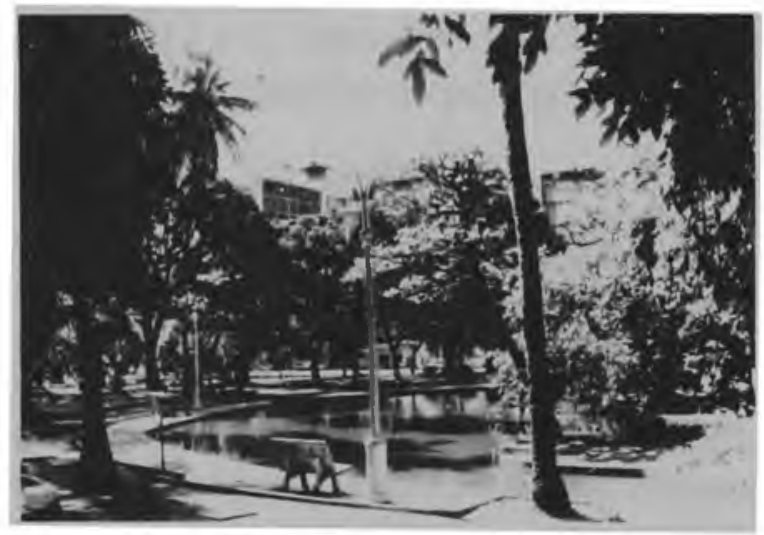

Foto 9 - Parque 13 de Maio - lago serpentiforme e ilhote - a narca do ecletismo pitoresco no paisagismo

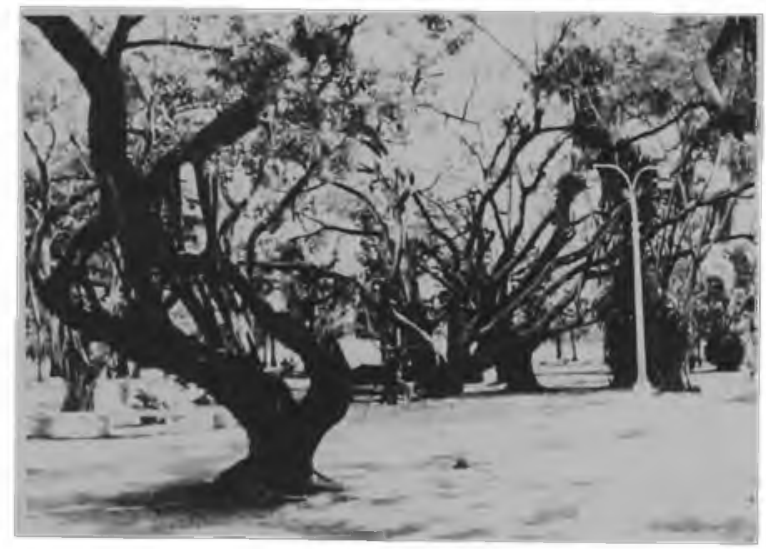

Foto 10 - Parque 13 de Maio arvoredo típico. Durante todo o século o pàrque passou por diversas alterações, com a introdução, por exemplo, de modemos bancos e um play-ground, reformas estas que não chegaram a alterar totalmente sua estrutura morfológica básica 
O clímax do Paisagismo em Pernambuco se deu com a vinda de Roberto Burle Marx para participar da Diretoria de Arquitetura e Urbanismo, liderada por Luiz Nunes. no período entre 1934 e 1937 onde atuou como Diretor de Parques e Jardins. Sua grande contribuição, além da arte de projelar as belas praças da época, foi a introdução do uso de plantas nativas em associaçðes representativas de regiões fitogeográficas distintas, como é o caso da praça Euclides da Cunha, com espécies da caatinga. e da praça de Casa Forte que, dividida em três blocos, tem espécies da Amazônia, da América do Sul e exótica. O trabalho de Burle Marx em Pernambuco continuou apesar de sua partida em 1937, através de projetos isolados de pequenos e grandes portes, institucionais e privados. Esse paisagismo tinha uma relação com a obra arquitetônica existente formando uma excelente unidade plástica, como é o caso da praça do Aeroporto, na década de 50 e o jardim da Celpe na década de 70.
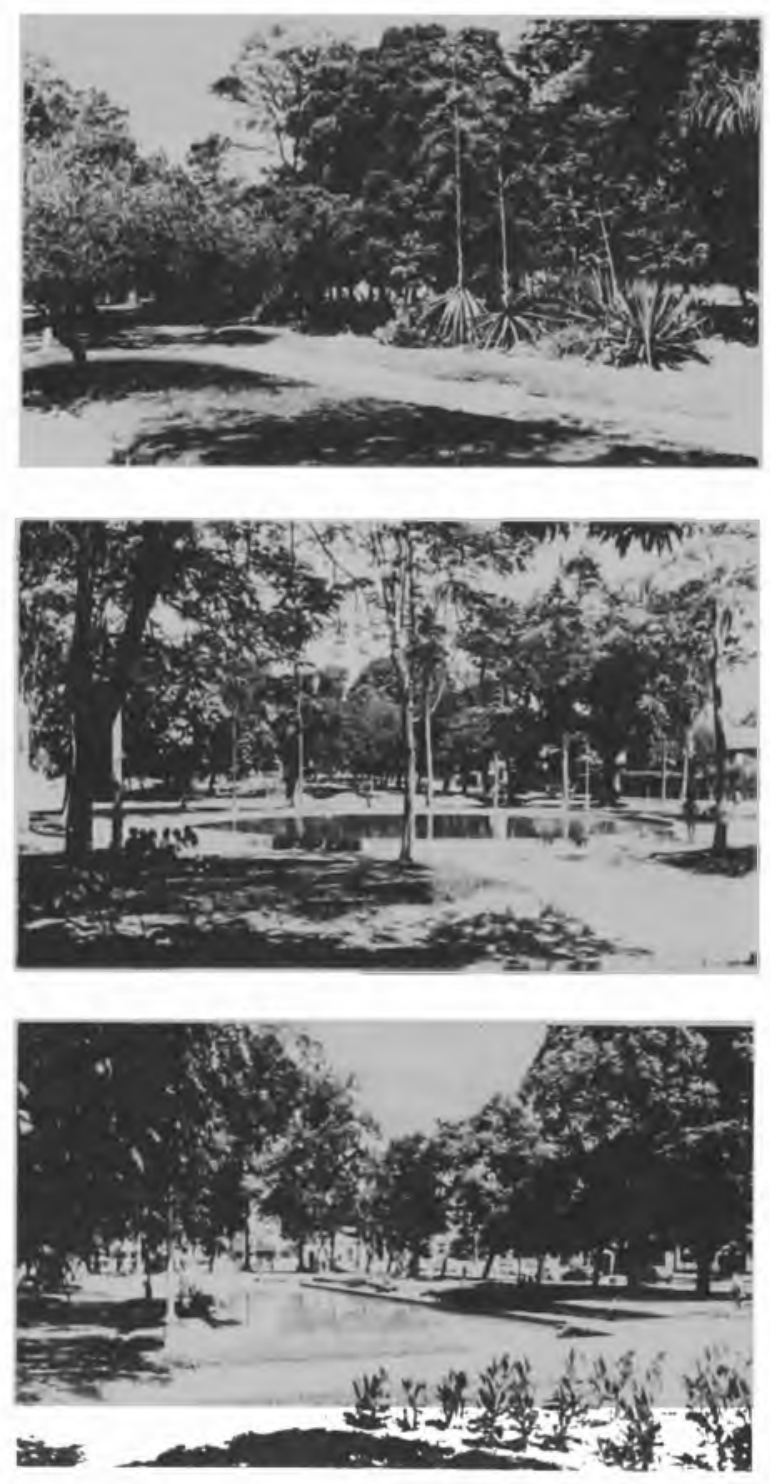

Foto 11 - Praça Euclides da Cunha vista geral

Foto 12 - Praça de Casa Forte esta praça localizada cm um bairro residencial de Recife é um marco da obra de Burle Marx no Recife, constituindo-se de três partes distintas, cada uma apresentando um cenário especial

Foto 13 - Praça de Casa Forte vista geral 


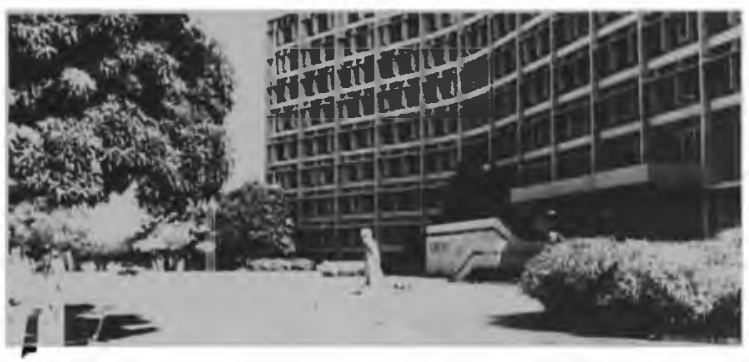

Folo 14 - Jardim frontal do prédio da

CELPE - Centrais Elétricas de

Pemambuco, marcando a presença

da obra do Burle Marx

contemporâneo. com formas de

piso e águas de características

nitidamente geométricas

Pernambuco, é deficiente na formação do arquiteto paisagista. Não existe curso de nível superior, revista especializada ou uma bibliografia farta. O CREA atribui a prática profissional de paisagismo ao arquiteto e ao engenheiro agrônomo, porém, nenhum dos dois profissionais tem uma formação específica. $O$ único curso em Composição Paisagística no Brasil é ministrado na escola de Belas Artes da UFRJ, mas a profissão de paisagista não é regulamentada e, conseqüentemente, o profissional não pode obter o CREA.

No estado o Paisagismo não teve uma Escola Acadêmica, mas sim uma "escola" empírica que buscou seu aprendizado nas diversas intervenções e principalmente na obra e no convívio de Burle Marx, sendo os novos paisagistas responsáveis por obras diversas. $O$ curso de arquitetura oferecia a opção de Paisagismo no trabalho de graduação e só em 1990 iniciou as disciplinas de Introdução ao Paisagismo I e II, que são importantes para a formação do arquiteto, mas insuficiente para a atuação do paisagista.

\section{NOTAS}

(1) Liana Mesquita é arquiteta e desenvolveu em Recife pesquisa visando reconstituir a estrutura morfológica dos jardins dos tempos de Nassau.

(2) MC HARG, Ian L. Design with Nature. p. 71.

(3) José Luiz da Mota Meneses é arquiteto e historiador e organizador do Atlas Histórico Cartográfico do Recife. FUNDAJ, Editora Massagana, 1988.

(4) Louis Léger Vauthier, engenheiro francês, chegou ao Recife por volta de 1840 e ficou até 1843. Veio para dirigir as obras públicas durante o governo do Conde da Boa Vista. No Recife fez o projeto do Teatro Santa Isabel e deu início às suas obras. Em Paris participou da adaptação do Mercado de São José, que tem estrutura em ferro, para o Recife.

\section{BIBLIOGRAFIA}

Mc HARG, Ian. Design with nature. New York: Doubleday Natural History Press Garden City, 1971.

MENEZES, José Luis da Mota. Atlas Histórico e Cartográfico de Recife. Recife: Massagana, 1988.

Fotos: Fornecidas pelo autor. 